American Journal of Economics and Business Administration 1 (2): 167-172, 2009

ISSN 1945-5488

(C) 2009 Science Publications

\title{
The Impact of CRM on the Customer Satisfaction in Agricultural Bank
}

\author{
Mohammad Ali Sarlak and Rasool Sanavi Fard \\ Department of Management, Payame Noor University, Iran
}

\begin{abstract}
Problem statement: There is much research on this subject, but none of them is about the use of customer relationship management for boosting the bank customer satisfaction. While we have not any study about customer satisfaction in Agricultural Bank especially in Qom providence. Approach: The research method was applied one and from viewpoint of the process, was considered to be descriptive-survey. This research in which statistical analysis methods, such as Friedman's variance analysis, binomial test as well as single-sample Student's t test, were used. Since there were numerous samples in the research population (which includes the customers of Agricultural Bank), it was supposed to be infinite. Simple random sampling method had been used to determine the number of the customers of Qom province's Agricultural Bank among which 384 the sample size for this statistical research. At the present research, customer relationship management was considered to be an independent variable: its variables included services quality, access to services and their properties. Office of customer complaints was considered as an independent variable, while the customer satisfaction is a dependent variable. Results: Considering the table results, highest rank was related to services access with a mean rank of 2.96 while lowest rank with the mean value of 2.18 , is for the office of customer complaints. Considering the results of the table above it can be found that for the bank referrers, "to behave respectfully" and "not be tiresome the queue" were considered as the most and the least important indexes, respectively, finally let to confirm all hypotheses. Conclusion: As per research result, there was positive relationship between customer relationship management and customer satisfaction in Agricultural Bank, Qom providence. Since the suggestions will be proposed based on the results obtained from hypothesis testing, recommendation had been mentioned for boosting the customer satisfaction.
\end{abstract}

Key words: Services access, service quality, property of services, office of the customer complaints

\section{INTRODUCTION}

The last several years saw the rise of Customer Relationship Management (CRM) as important business approach. CRM is a strategy that goes beyond increasing transaction volume. Its objectives are to increase profitability, revenue and customer satisfaction. To achieve CRM, a company wide set of tools, technologies and procedures promote the relationship with the customer to increase sales ${ }^{[3]}$. Nowadays with advancing information technology, there are modern systems that can help to increase the organization power with the purpose of decreasing internal expenses, making better interaction with the environment and finally obtaining the economic profit $^{[1]}$.

Customer relationship management is considered to be one of the above-mentioned tools, which as a business strategy, has tendency to select and manage the most valuable relationships with the customers. Customer relationship management consists of three components, i.e., customer, relationship and management: It tries to show a single view to its customers, while looking for a customer-centric viewpoint ${ }^{[2]}$.

So it would be expected to help the banks improve their abilities to plan sale operations as well as marketing campaigns and provide services through the different ways of interaction with customer companies (including person-to-person communication, telephone, fax, web network, direct mail and e-mail). The bank customers can be divided into five categories: Depositors, loan takers, openers of letter of credits, users of some special services (sending draft, issuing inter-bank cheque, paying water and electricity bill and so on) and third parties (bank security).

On the other hand, the key customers can be identified based on special criteria through database available in the bank, including the time period

Corresponding Author: Rasool Sanavi Fard, Department of Business Management, Payame Noor University, Rahahan, Garmsar, Iran, Tel: +982324230993 Fax: +982324229991 
during which there is an account in the bank, the average cash during the year, continuation of bank operations, the number of bank referring, as well as the experiences of branch managers and their employees.

To develop stable relations with the customers, Stone and Dodkak proposes an eight-step model to be described as in Fig. 1.

Welcoming: After the potential customer made his/her first purchase and converted into a customer, it is important to make some effort for continuing (or repeating) his/her buying behavior.

Getting acquainted: This stage may play a sensitive role in developing relations with the customers as well as converting him/her as a lord. Banks want to know on the present and/or future financial needs as well as plans and wants of the customers.

Customer account: At this stage, some efforts will be made for managing a secure relationship. Considering the customer relationship, it leads the managers to provide more the customer needs.

Intensive care: There are a lot of problems to be happened in the relationship between the bank and its customers, which would be expected to lead to some risk for continuing of the present relationship.

It can be said that it feels to be more necessary in the stage of account management. Since a customer may be able to use different bank services, the bank is expected to be on the look out the circumstances in order to prevent the customer from switching bank.

Potential divorce: If there was no intense care for providing the customer satisfaction, his/her divorce and exit may be occurred-the phenomenon that most banks ignore it.

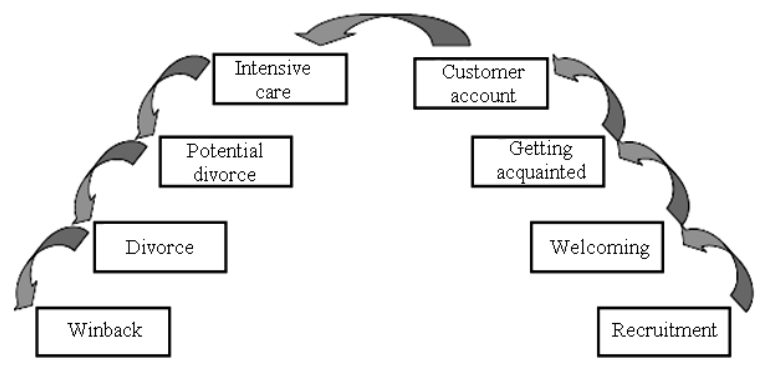

Fig. 1: Eight-stage model for developing relations with the customers
Divorce: If the bank doesn't try to change properly the present circumstances, the customer, by closing his/her accounts may interrupt the relation with the institution, switching the bank.

Winback: Winbacking successfully a customer usually depends upon the reasons of the customer to switch bank, among which those resulting from unsatisfying the received services demands that it is required to create closer links between the bank and its customers $^{[4]}$.

Although there are many investigations on customer relationship management, the present research focuses on the impact of customer relationship management on the customer satisfaction in Agricultural Bank.

This research is intended to realize the impact of customer relationship management on the customer satisfaction, identify economic motivations and reasons for trading with the customers and its impact on gaining comparative advantage, as well as confirm the fact that customer relationship management is considered to be an approach by which the managers and experts may be able to use new managerial tools and viewpoints.

\section{MATERIALS AND METHODS}

The research method is an applied one and from viewpoint of the process, is considered to be descriptive-survey. Since there are numerous samples in the research population (which includes the customers of Qom province's Agricultural Bank), it is supposed to be infinite, while sampling method used for determining the number of the random customers is simple.

Sampling method is the classified random sampling, in which there is equal chance of selecting each one of the population elements in the intended class. Considering the mentioned cases, the sample size used by researcher is determined through the following formula in which $\varepsilon$ (limit error) depends upon the selected sample; the maximum limit error that can be taken into consideration lies between $10-12 \%{ }^{[5]}$.

Since no index is available as variance of the study population and there is no prior history about the subject, the mean value and variance were not predetermined. Therefore, in order to increase the confidence with a lower error, highest possible standard deviation of the population, i.e., $50 \%$, is set instead of the possible standard deviation. So $\varepsilon=0.05$ and $\delta=0.5$ and consequently, $\mathrm{n}$ has the maximum number. As a result, considering the subjects above, sample size of 
the research consequently includes 384 customers of the population:

$$
\mathrm{n}=\left(\frac{\mathrm{z} \alpha / 2 \times \partial}{\varepsilon}\right)
$$

Where:

$\mathrm{z}=1.96$ is the standard number at the confidence coefficient of $95 \%$

$\partial=$ Std. deviation

$\varepsilon=$ Limit error

$\mathrm{n}=$ The number of sample $\mathrm{e}^{[5]}$

To estimate the questionnaire reliability, Cronbach alpha method has been used; finally, the results of SPSS showed that reliability of the questions were calculated to be 0.8 .

The questions relating to research hypotheses include 25 five-option statements, designed on the basis of Likert spectrum ${ }^{[6]}$.

Research variables: At the present research, customer relationship management is considered to be an independent variable: Its factors (variables) include services quality, access to services and their properties. Office of customer complaints is considered as an independent variable, while the customer satisfaction is a dependent variable. Characteristics has been shown in Table 1.

\section{RESULTS}

Ranking the quadruple factors forming the CRM: For ranking the quadruplet factors forming customer relationship management, Friedman test is used, the results of which are shown in the Table 2 .

Ranking the variables of CRM on the basis of its impact on the customers satisfaction: Considering the Table 3 results, highest rank is related to services access with a mean rank of 2.96 while lowest rank with the mean value of 2.18, is for the Office of customer complaints.

Considering Friedman test, the degree of importance of the present indexes has been considered.

According to the obtained results, the p-value of test statistic is equal to zero, which makes the indexes even more different from the responder's viewpoint Considering the results of the Table 3 it can be found that for the bank referrers, "to behave respectfully" and "not be tiresome the queue" are considered as the most and the least important indexes, respectively.

Table 1: Criteria (characteristics) of the questionnaire

\begin{tabular}{|c|c|c|}
\hline Variables & Indexes & Indicators \\
\hline \multirow[t]{17}{*}{ Service quality } & \multirow{4}{*}{$\begin{array}{l}\text { Physical and tangible } \\
\text { evidences }\end{array}$} & Modern bank equipments \\
\hline & & Attractiveness of physical facilities \\
\hline & & Being clean and adorned with formal uniform \\
\hline & & Equipments, items, forms and documents with beautiful design and appearance \\
\hline & \multirow{3}{*}{ Validity } & Practical commitment of branch employees and managers \\
\hline & & Truthful action to resolve problems of the customers \\
\hline & & Providing services without any mistake \\
\hline & \multirow[t]{2}{*}{ Responsibility } & Providing promptly the services \\
\hline & & Being eager in their interactions with the customers \\
\hline & \multirow[t]{8}{*}{ Peace of mind } & Feeling security among the customers in their interactions \\
\hline & & Behaving respectfully and politely with the customers \\
\hline & & Having proper knowledge and skill for answering the customers' questions \\
\hline & & Working hours to be desirable for the customers \\
\hline & & Understanding the special needs and expectations of any customer \\
\hline & & Acting according the customer wants and interests \\
\hline & & A paltry bank-received fee for the services \\
\hline & & Non-boring queue \\
\hline \multirow[t]{3}{*}{ Access to services } & \multirow[t]{3}{*}{ Accessibility } & Development of bank branches \\
\hline & & Geographical location of bank branches \\
\hline & & Using remote systems for providing services \\
\hline \multirow[t]{3}{*}{ Properties of services } & \multirow[t]{3}{*}{ Communications } & Various bank services \\
\hline & & Modern and innovative services \\
\hline & & Unique bank services, compared to other banks \\
\hline Office of customer complaints & & Providing services upon the customer demand \\
\hline
\end{tabular}


Am. J. of Economics and Business Administration, 1 (2): 167-172, 2009

Table 2: Ranking quadruplet factors forming the customer relationship management

\begin{tabular}{ll}
\hline Quadruplet factors forming the CRM & Mean of the ranks \\
\hline Access to services & 2.96 \\
Service quality & 2.49 \\
Properties of services & 2.38 \\
Office of the customer complaints & 2.18
\end{tabular}

Table 3: Ranking the variables of CRM on the basis of its impact on the customer satisfaction

\begin{tabular}{ll}
\hline & $\begin{array}{l}\text { Mean of } \\
\text { the ranks }\end{array}$ \\
Indexes & 9.64 \\
\hline Behaving respectfully and politely with the customers & 8.86 \\
Being orderly and adorned with formal uniform & 8.86 \\
Working hours to be desirable for the customers & 8.76 \\
Having proper knowledge and skill for answering the & \\
customers' questions & 8.64 \\
Practical commitment of branch employees and managers & 8.57 \\
Truthful action to resolve problems of the customers & 8.42 \\
Providing services without any mistake & 7.20 \\
Equipments, items, forms and documents with beautiful & \\
design and appearance & 7.19 \\
Being eager in their interactions with the customers & 6.83 \\
A paltry bank-received fee for the services & 6.47 \\
Feeling of a winner in bank transactions & 6.35 \\
Understanding the special needs and expectations of & \\
any customer & 6.22 \\
Attractiveness of decoration and physical facilities of & \\
bank branches & 3.17 \\
Non-boring queue &
\end{tabular}

\section{DISCUSSION}

Principal hypothesis testing: This hypothesis concerns as to whether or not there is any relationship between customer relationship management and customer satisfaction. In other words, null hypothesis and alternative hypothesis are as follow:

\section{Hypotheses:}

$\mathrm{H}_{0}$ : Using the method by the bank is independent from the customer satisfaction

$\mathrm{H}_{1}$ : Using the method by the bank has influence on the customer satisfaction

For the hypothesis testing above, a binomial test can be used, in which the results have been obtained by comparing with score 3 (average level)

The results obtained from statistical test as per Table 4 show that since the significance number is zero, i.e., an amount lower than level of significance of $0.05 \%$, the hypothesis $\mathrm{H}_{0}$ can not be confirmed; it means null hypothesis is rejected. On this basis, we can accept that these two factors are not independent from each other, having influence on each other; it means the customers are satisfied with the bank.
Table 4: The results obtained from binomial test on the impact of CRM on the customer satisfaction

\begin{tabular}{lcc}
\hline Indexes & Group $1 \leq 3$ & Group $2<3$ \\
\hline Asymp. Sig. (2-tailed) & $0.00(\mathrm{a})$ & \\
Testing ratio & 50.00 & \\
Std. deviation & 0.72 & 0.28 \\
Number & 241.00 & 94.00 \\
\hline
\end{tabular}

Table 5: The indexes obtained for first sub-hypothesis

\begin{tabular}{lrlr}
\hline Indexes & Result & Indexes & \multicolumn{1}{c}{ Result } \\
\hline Mean & 13.13480 & Number & 335.000 \\
Median & 3.21430 & Level of Sig. & 0.000 \\
Std. deviation & 0.56235 & Skewness & -0.045 \\
Variance & 0.31600 & Statistic & 4.388 \\
Kurtosis & 0.24900 & Degree of freedom & 335.000 \\
\hline
\end{tabular}

First sub-hypothesis: The quality of bank-provided services has influence on the customer satisfaction. Null hypothesis is considered to be independence of these two factors. In other words:

\section{Hypotheses:}

$\mathrm{H}_{0}$ : The quality of bank-provided services is independent from the customer satisfaction

$\mathrm{H}_{1}$ : The quality of bank-provided services has influence on the customer satisfaction

Table 5 shows that there is a test statistic of 4.38 . Furthermore, since there is a level of significance of lesser than $0.05 \%$, the alternative hypothesis will be confirmed, indicating the presence of a relationship and being dependence these two factors.

On the other hand, the mean of the answers for the hypothesis above, is equal to 3.1348 , indicating the fact that this method in the bank has influence on the customer satisfaction. The upper and lower bounds of confidence interval that considered for mean of the answers is equal 0.1953 and 0.0744 , i.e., the mean of the answers lies in the mentioned interval, with a confidence of 0.95 . In the meantime, since the median is more than mean value it can be said that there is skewness to the left in distribution of the answers. In other words, the concentration of the distribution is toward the right, i.e., tendency to the value of 5 (very high), indicating positive relationship between customer relationship management and the customer satisfaction.

Second sub-hypothesis: It concerns the amount that the customer's access to bank services has influence on the customer satisfaction. It should be borne in mind that here null hypothesis is considered to be independence of those two factors. 
Am. J. of Economics and Business Administration, 1 (2): 167-172, 2009

Table 6: The indexes obtained for the second sub-hypothesis

\begin{tabular}{lclr}
\hline Indexes & Result & Indexes & \multicolumn{1}{c}{ Result } \\
\hline Mean & 3.3301 & Number & 335.000 \\
Median & 3.5000 & Level of Sig. & 0.000 \\
Std. deviation & 0.8750 & Skewness & -0.300 \\
Variance & 0.7660 & Statistic & 6.906 \\
Kurtosis & -0.3910 & Degree of freedom & 334.000 \\
\hline
\end{tabular}

Table 7: The indexes obtained for third sub-hypothesis

\begin{tabular}{lclr}
\hline Indexes & Result & Indexes & \multicolumn{1}{c}{ Result } \\
\hline Mean & 3.15910 & Number & 335.000 \\
Median & 3.00000 & Level of Sig. & 0.008 \\
Std. deviation & 1.09267 & Skewness & 6.424 \\
Variance & 1.19400 & Statistic & 2.665 \\
Kurtosis & 83.29500 & Degree of freedom & 334.000 \\
\hline
\end{tabular}

\section{Hypotheses:}

$\mathrm{H}_{0}$ : The amount of the customers' access to bank services is independent from the customer satisfaction

$\mathrm{H}_{1}$ : The amount of the customers' access to bank services has influence on the customer satisfaction

According to Table 6, considering the level of significance to be lesser than $0.05 \%$, here the null hypothesis is rejected, while we accept this hypothesis that there is a mutual influence between the two factors. As far as the factor is concerned, the upper and lower bounds of a $95 \%$ confidence interval are 0.4242 and 0.2361 ; i.e., with the same confidence value it can be said that there is a certain relationship. Furthermore, the Table 6 shows that since median value is more than mean value, we witness a positive relationship between the intended factors.

Third sub-hypothesis: The properties of the bankprovided services have influence on the customer satisfaction. As in previous case, null hypothesis and alternative hypothesis can be defined as follows:

\section{Hypotheses:}

$\mathrm{H}_{0}$ : The properties of the provided services are independent from the customer satisfaction

$\mathrm{H}_{1}$ : The properties of the bank-provided services have impact on the customer satisfaction

Here we can accept the mutual impact of the two factors on each other since the level of significance has been lesser than $0.05 \%$. Furthermore, considering the confidence interval which looks as follows, it can be said that to a confidence of $95 \%$ we are sure the null hypothesis to be rejected. Since the Table 7 shows a median lesser than mean value, there is a tendency toward the left in the factor distribution; it means the relationship approaches to weak relationship.
Table 8: The indexes obtained for fourth sub-hypothesis

\begin{tabular}{lclr}
\hline Indexes & Result & Indexes & \multicolumn{1}{c}{ Result } \\
\hline Mean & 2.96570 & Number & 335.000 \\
Median & 3.00000 & Level of Sig. & 0.458 \\
Std. deviation & 0.84477 & Skewness & \\
Variance & 0.71400 & Statistic & -0.744 \\
Kurtosis & -0.14300 & Degree of freedom & 334.000 \\
\hline
\end{tabular}

Fourth sub-hypothesis: It tries to express the effective relationship between the performances of the Office of Customer Complaints and the customer satisfaction, which can be considered as follows:

\section{Hypotheses:}

$\mathrm{H}_{0}$ : The performance of the Office of Customer Complaints in the bank is independent from the customer satisfaction

$\mathrm{H}_{1}$ : The performance of the Office of Customer Complaints in the bank has influence on the customer satisfaction

Here, as before, since the level of significance is lesser than $0.05 \%$, in a $95 \%$ confidence interval, null hypothesis is rejected while its alternative hypothesis concerning the mutual impact of the two factors on each other is confirmed. Since the Table 8 shows median value more than mean value, distribution of the factor is skewed to left.

\section{CONCLUSION}

- According to the respondents in the Qom province' Agricultural Bank, it can be said that the relationship between customer relationship management and customer satisfaction from the bank was confirmed. In other words, it can be said that the bank customers are satisfied with customer relationship management

- According to the respondents in the Agricultural Bank of Qom province, it can be said that the quality of the bank-provided services influences on the customer satisfaction

- According to the respondents in the Agricultural Bank of Qom province, it can be said that the index of access to bank-provided services influence on the customer satisfaction

- According to the respondents in the Agricultural Bank of Qom province, it can be said that the index of the property of investigating the complaints of the customers has no influence on the customer satisfaction, there is a weak influence between the two factors 
Suggestions: Since the suggestions will be proposed based on the results obtained from hypothesis testing, the following cases can be mentioned for boosting the customer satisfaction:

- $\quad$ Promptitude of the employees: Identifying suitable ways for increasing Promptitude of the employees: engaging those with higher Promptitude for providing bank services when there is a crowd around the bank counter; using enough workforces behind the bank counter and adapting new technology to increase the working readiness and quality

- Using proper technology: Studying and comparing the services of your bank with of the other banks while optimizing it and increasing the speed and quality of providing services. Of the reasons of the customer dissatisfactions, the most important which is frequently emphasized, is the low speed of providing the bank services

- Technical knowledge of the employees: With concentration on and more attention to add their abilities through educating, providing suitable incentives as well as increasing inclination to answering and guiding the customers, the costumer satisfaction can be drawn more than the past

- Customer Awareness: Creating a separate unit in marketing department to do advertisement, design the proper advertising banners and brochures by which suitable information on how to use the services will be given to the customers; as well as obligating the managers of the bank branches to distributing brochures between the customers and/or creating a teller telephone line explaining all organization services and products for the customers

- Seeming factors: Being beautiful decoration and items forms used by the customers and employees uniforms; obligating the managers of bank branches to observe seeming factors (adornment of the employees with formal uniform, steady cleansing of the branches) using artists, if possible

- How to behave with the customer: When engagement, the people need to be examined, considering the mental and personality properties, as to whether or not their morale conform with the state of behaving with the customer, being in mood to answer him/her as well as showing curtsy
Furthermore emphasizing the importance of observing politeness to and respect for the customers and paying attention to them, as well as compiling an instruction on how to answer the customers.

\section{REFERENCES}

1. Thompson, B., 2006. What is CRM? In the customer relationship primer. http://www.theresource-

center.com/BOOKS/CRM/Customer_relationship_ management.HTM

2. Gray, P. and B. Jongbok, 2001. Customer relationship management. http://www.tupublicas.com/docs/12-44-15-022004-leyva.pdf

3. Sarah L. Roberts-Witt, 2000. 5 Components of CRM. PC Magazine. http://www.tupublicas.com/docs/12-44-15-022004-leyva.pdf

4. Stone and Dudkak, 2001. Written by Amir safari. http://amirsafari.persianblog.ir/post/9

5. Adel, A. and M. Momeny, 2006. Statistic and Its Application in Management, 2. Samt Publishers in Tehran, Publish No. 5, ISBN: 964459973X, pp: 45-104.

6. Fotohi, A., 2002. Theory and Method of Social Statistics. Kanon Nashre Olom Publishers in Tehran, No. 1, ISBN: 9646463118. 